\title{
Bulk and Surface Defects in Nanoporous $\mathrm{SiO}_{2}$ Ceramic
}

\author{
V S Kortov ${ }^{1}$, A F Zatsepin, V B Guseva, V A Vazhenin, M Yu Artyomov \\ Ural Federal University, 620002, Ekaterinburg, Russia \\ E-mail: v.kortov@mail.ustu.ru
}

\begin{abstract}
The methods of electron paramagnetic resonance and optically stimulated electron emission have been used to study the conversion of defects in samples of a nanostructured $\mathrm{SiO}_{2}$ ceramic synthesized by the thermal decomposition of polysilazane $\mathrm{H}_{\mathrm{x}} \mathrm{C}_{\mathrm{y}} \mathrm{N}_{\mathrm{z}} \mathrm{Si}$. The ceramic samples additionally underwent a thermal treatment and were exposed to accelerated electrons.
\end{abstract}

\section{Introduction}

Silica is one of the most important materials in optics and semiconductor engineering, but so far the specific features of the formation and conversion of defects in its different low-dimensionality modifications have been poorly understood. One of the possible methods for investigating these materials is the electron paramagnetic resonance (EPR), which provides data not only on the concentration of defects, but also on their nature considering the values of the g-tensor and the superfine interaction constants. The information capacity of EPR can be expanded by the use of additional spectroscopic techniques.

The aim of this work was to study the nature of defects in porous nanostructured $\mathrm{SiO}_{2}$ and the effect of the low dimensionality on their magnetic and photoemission properties.

\section{Experimental}

The objects of study were silica samples synthesized by the thermal decomposition of polysilazane $\mathrm{H}_{\mathrm{x}} \mathrm{C}_{\mathrm{y}} \mathrm{N}_{\mathrm{z}} \mathrm{Si}$ in air. They were a nanostructured porous ceramic. The basic characteristics of the samples after different thermal treatment regimes are given in table 1.

The samples 1-3 were exposed to electrons (an energy $\mathrm{E}=10 \mathrm{MeV}$ and a fluence $\Phi=10^{16} \mathrm{~cm}^{-2}$ ) in an M-20 accelerator-microtron. The EPR spectra were measured in a 3-cm spectrometer with a highfrequency modulation of the magnetic field. It allowed making measurements in fields as high as 7.5 kGs, was equipped with devices for adjustment, stabilization, and measurement of the temperature, and was outfitted with a computer system for recording of spectra.

1 The corresponding author. 
11th Europhysical Conference on Defects in Insulating Materials (EURODIM 2010)

IOP Publishing IOP Conf. Series: Materials Science and Engineering 15 (2010) 012066 doi:10.1088/1757-899X/15/1/012066

Table 1. Characteristics of nanoporous $\mathrm{SiO}_{2}$ samples.

\begin{tabular}{|l|l|l|}
\hline $\begin{array}{l}\text { Type of } \\
\text { sample }\end{array}$ & $\begin{array}{l}\text { Synthesis method and annealing } \\
\text { conditions }\end{array}$ & Structural features \\
\hline 1 & $\begin{array}{l}\text { Heating of polysilazane at } \mathrm{T}=600^{\circ} \mathrm{C} \text { for } \\
\text { hours in air }\end{array}$ & $\begin{array}{l}\text { Amorphous, porous structure, skeleton density } \\
\text { of } 2.42 \mathrm{~g} / \mathrm{cm}^{3}\end{array}$ \\
\hline 2 & $\begin{array}{l}\text { Annealing of the samples } 1 \text { at } \mathrm{T}=1000^{\circ} \\
\text { for } 6 \text { hours in air }\end{array}$ & $\begin{array}{l}\text { Amorphous, porous structure, skeleton density } \\
\text { of } 1.89 \mathrm{~g} / \mathrm{cm}^{3}\end{array}$ \\
\hline 3 & $\begin{array}{l}\text { Annealing of the samples } 1 \text { at } \mathrm{T}=1400^{\circ} \\
\text { for } 6 \text { hours in air }\end{array}$ & $\begin{array}{l}\text { Porous structure, skeleton density of } 1.40 \mathrm{~g} / \mathrm{cm}^{3}, \\
\text { with nanoscale crystalline inclusions }\end{array}$ \\
\hline 4 & $\begin{array}{l}\text { Decomposition of initial polysilazane in } \\
\text { a vacuum at a temperature of } 1000^{\circ} \mathrm{C}\end{array}$ & $\begin{array}{l}\text { An X-ray diffraction analysis revealed the } \\
\text { presence of nanoscale } \mathrm{Si}_{3} \mathrm{~N}_{4} \text { and } \mathrm{SiC} \text { (at least } \\
50 \%), \mathrm{C}, \text { and } \mathrm{SiO}_{2} \text { impurity }\end{array}$ \\
\hline
\end{tabular}

The spectra of nonstationary optically stimulated electron emission (OSEE) in the range of 4.9 to $6.2 \mathrm{eV}$ were measured at room temperature in a vacuum of $10^{-4} \mathrm{~Pa}$ using a VEU-6 secondary emission multiplier as an electron detector. The samples were excited by the light of a DDC-30 deuterium lamp with a DMR-4 monochromator. The method of processing the measured spectra is described in detail elsewhere [1].

\section{Results}

According to the results of the electron microscopic examination, the surface of the samples had characteristic nanostructural pores about $100-500 \mathrm{~nm}$ in size, which could appear due to the release of the gaseous phase (figure 1). Some ordering of the spatial distribution of pores in the samples is worthy of note since it adduces evidence that this material later can be the basis for development of ordered nanostructures.

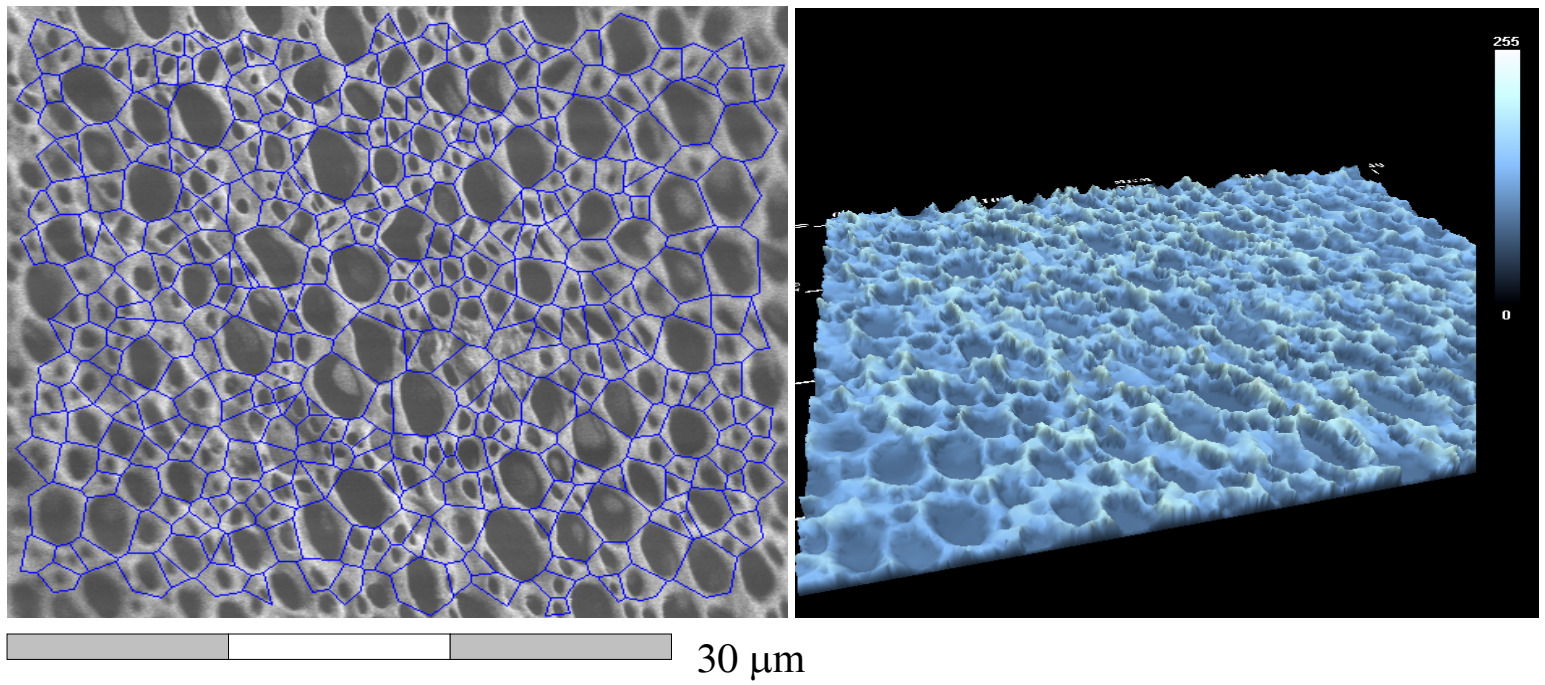

Figure 1. Electron microscope image (left) and a 3-D reconstruction of the surface (right) of nanoporous silica (sample 3).

The measurements of EPR spectra, which were performed on the unirradiated samples 1-3 at temperatures of 300 and $163 \mathrm{~K}$, did not reveal the presence of paramagnetic defects in concentrations sufficient for the measurements. Oppositely, a narrow intensive signal with the g-factor close to 2, 
which was stable in air, was observed in the samples 4 . Figure 2 depicts a spectrum, which was obtained by simultaneous recording of the above signal and a signal of a DPPH (diphenyl-picrylhydrazyl) test sample. As determined from the measurements at room temperature, the g-factor of the signal of the samples under study was 2.0026. For the DPPH test sample the g-factor was $g=2.0036$.

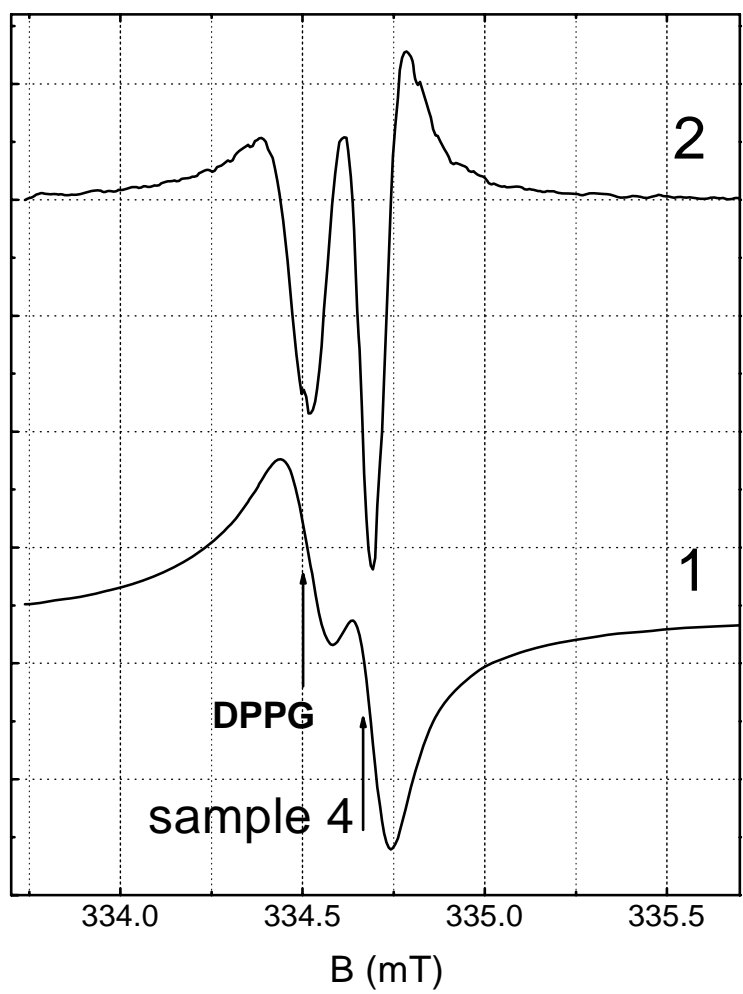

Figure 2. First (1) and second (2) derivatives of the absorption signal from the sample 4 and a DPPH sample.

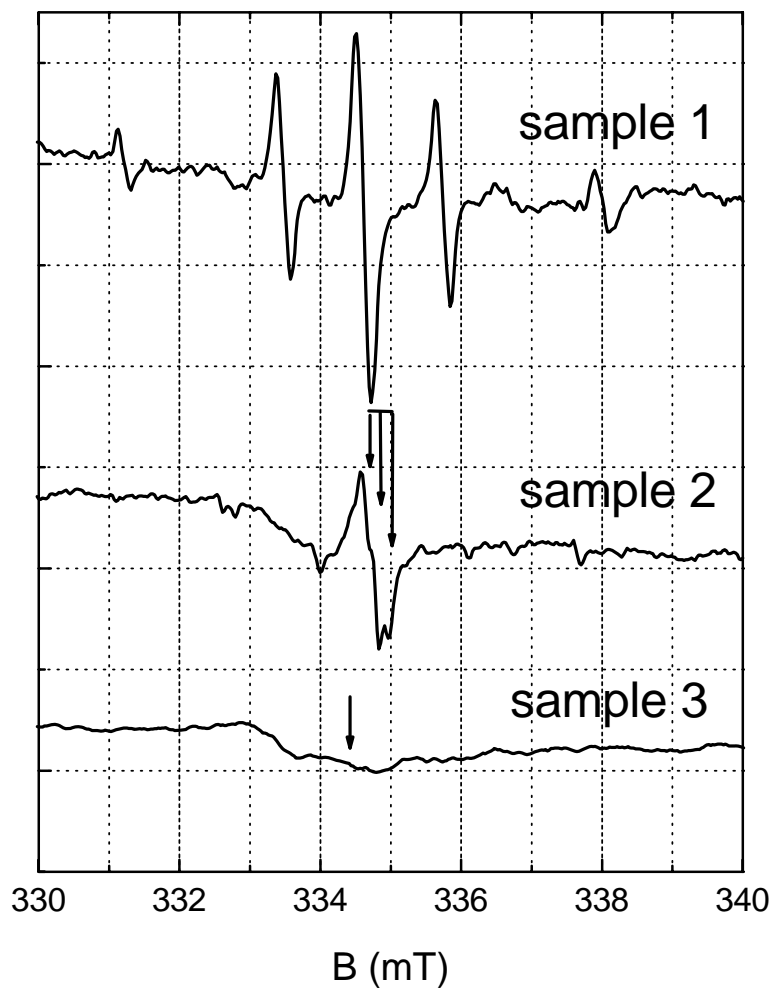

Figure 3. EPR spectra of the samples of different types of nanoporous $\mathrm{SiO}_{2}$ irradiated at room temperature.

The exposure to fast electrons, which was aimed at producing a high concentration of paramagnetic defects, did not lead to visible changes in the spectrum of the samples 4, but had a considerable effect on the spectra of the samples 1-3 (figure 3). The basic parameters of the EPR spectra are given in table 2.

The results of measurements of the OSEE spectra of the samples 1-3 are shown in figure 4. The parameters of the computer-simulated spectral lines are given in table 3.

\section{Discussion}

The measurement results demonstrated that the lines of the spectrum of the samples 4 were most intense (see figure 2). According to the X-ray diffraction analysis, these samples contained both carbon and silicon carbide. It is known that a narrow isotropic air-stable signal with a similar g-factor (2.0029) was observed in mechanically broken diamond and silicon carbide. It was related to a broken covalent bond of a ${ }^{12} \mathrm{C}$ atom [2]. 
11th Europhysical Conference on Defects in Insulating Materials (EURODIM 2010)

IOP Publishing IOP Conf. Series: Materials Science and Engineering 15 (2010) 012066 doi:10.1088/1757-899X/15/1/012066

Table 2. Parameters of the EPR spectrum and types of defects in nanoporous $\mathrm{SiO}_{2}$.

\begin{tabular}{|c|c|c|c|}
\hline $\begin{array}{l}\text { Type of } \\
\text { sample }\end{array}$ & g-factor & Specific features of the spectrum & $\begin{array}{l}\text { Assumed type of } \\
\text { defect }\end{array}$ \\
\hline 1 & $\begin{array}{l}2.0026(3) \\
2.0026(3)\end{array}$ & $\begin{array}{l}\text { A structure of four lines, the central-to-side line } \\
\text { intensity ratio of } 3: 1 \text {, the line spacing of } 2.25(5) \\
\mathrm{mT} \text {, the line with of } 0.25 \mathrm{mT}\end{array}$ & $\begin{array}{l}\text { Methyl radical }{ }^{\bullet} \mathrm{CH}_{3} \\
{ }^{12} \mathrm{C} \cdot\end{array}$ \\
\hline 2 & $\begin{array}{l}2.0026 \\
2.0016 \\
2.0007\end{array}$ & $\begin{array}{l}\text { A complicated asymmetrical signal, the total line } \\
\text { width of } 0.9 \mathrm{mT}\end{array}$ & $\begin{array}{l}E^{\prime} \text {-centers (bulk and } \\
\text { surface) }\end{array}$ \\
\hline 3 & 2.0035 & Low-intensity, the line width of $0.9 \mathrm{mT}$ & $\begin{array}{l}\text { Oxygen-deficient } \\
\text { centers like } \mathrm{P}_{\mathrm{b}}\end{array}$ \\
\hline 4 & $2.0026(3)$ & Intensive, the line width of $0.25 \mathrm{mT}$ & Broken carbon bond \\
\hline
\end{tabular}

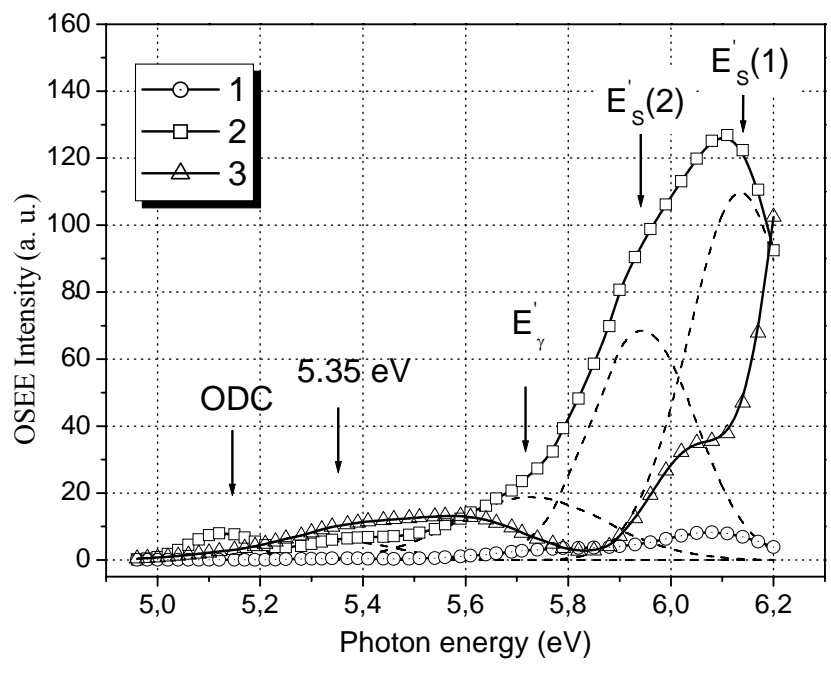

Figure 4. OSEE spectra for the samples 1-3 of $\mathrm{SiO}_{2}$.
Table 3. Positions of OSEE spectrum lines for samples of nanostructured $\mathrm{SiO}_{2}$ after a thermal treatment

\begin{tabular}{|c|c|c|c|}
\hline Sample & $\mathrm{E}, \mathrm{eV}$ & $\Delta \mathrm{E}, \mathrm{eV}$ & $\begin{array}{c}\text { Type of } \\
\text { defect }\end{array}$ \\
\hline 1 & 5.35 & 0.18 & $\mathrm{E}_{2}{ }^{\prime}$ \\
& 5.81 & 0.34 & $\mathrm{E}_{\gamma}{ }^{\prime}$ \\
& 6.09 & 0.20 & $\mathrm{E}_{\mathrm{S}^{\prime}(2)}$ \\
\hline 2 & 5.37 & 0.23 & $\mathrm{E}_{2}{ }^{\prime}$ \\
& 5.73 & 0.34 & $\mathrm{E}_{\gamma^{\prime}}$ \\
& 5.95 & 0.23 & $\mathrm{E}_{\mathrm{S}}{ }^{\prime}(2)$ \\
& 6.13 & 0.23 & $\mathrm{E}_{\mathrm{S}}{ }^{\prime}(1)$ \\
\hline 3 & 5.38 & 0.27 & $\mathrm{E}_{2}{ }^{\prime}$ \\
& 5.61 & 0.27 & $\mathrm{E}_{\gamma}{ }^{\prime}$ \\
& 6.04 & 0.20 & $\mathrm{E}_{\mathrm{S}^{\prime}}(2)$ \\
& 6.34 & 0.23 & $\mathrm{E}_{\mathrm{S}^{\prime}(1)}$ \\
\hline
\end{tabular}

A narrow signal with $g=2.0029$ can also be assigned to a defect related to an unpaired electron of a carbon atom. The line with the g-factor $=2.0027$, which was repeatedly observed in the EPR spectrum of the silicon surface [3], appears due to the presence of impurities containing carbon compounds. It can be assumed that the EPR signal of the samples 4 has an analogous origin and is related to centers of carbon with a broken covalent bond. These centers were present on the surface of the pores, which appeared during the thermal treatment. The line with $g=2.0026$ in the spectrum of the samples 1 (figure 3) can also be explained by the presence of broken-bond carbon centers localized in regions with high concentrations of $\mathrm{SiC}$ and $\mathrm{C}$. The intensity ratio and positions of the quartet components in 
figure 3 coincide well with the spectrum of the methyl radical ${ }^{\circ} \mathrm{CH}_{3}$, which can be part of polysilazanedecomposition organic compounds on the surface or in the bulk of the samples [4].

The EPR spectrum of the samples 2 (figure 3) has a complicated structure. Although the signal of ${ }^{12} \mathrm{C}$ can be present among the central lines of the spectrum of these samples, this region should be referred primarily to E' centers. The obtained values of the g-factor for the observed structure (2.0026, 2.0016 , and 2.0007) are close to those of an $\mathrm{E}_{\gamma}{ }^{\prime}$ center in amorphous silica $(2.0029,2.0017$, and 2.0015 [5]) and quartz glasses $\left(\mathrm{g}_{\|}=2.0018, \mathrm{~g}_{\perp}=2.0004\right.$ [6]). However, the same region can include signals of an $\mathrm{E}_{\mathrm{s}}^{\prime}$ center $\left(\mathrm{g}_{\|}=2.0018, \mathrm{~g}_{\perp}=2.0003[2]\right)$, which is a surface analog of an $\mathrm{E}_{\gamma}{ }^{\prime}$ center. Also, the data on the composition of the samples probably suggest the presence of ${ }^{\circ} \mathrm{C}-\mathrm{Si}_{3}$ centers with a broken bond of a carbon atom in the silicon environment.

The low-intensity broad signal with the g-factor of 2.0035 , which is observed in the spectrum of the samples 3 (figure 3), most probably is due to the defects related to a broken covalent bond of silicon. According to the optical spectroscopy data, the samples 3 are characterized by the presence of oxygen-deficient $\equiv \mathrm{Si}-\mathrm{Si} \equiv$ and $=\mathrm{Si}$ : centers, $\equiv \mathrm{SiSiSi} \equiv$ clusters, and nanoscale inclusions of crystalline silicon. Then it is probable that the exposure to accelerated electrons leads to the formation of paramagnetic $\equiv \mathrm{Si} \cdot$ centers analogous to $\mathrm{P}_{\mathrm{b}}$ centers observed in $\mathrm{Si}^{-} \mathrm{SiO}_{2}$ systems [7].

Thus, the EPR data point to a change in the composition of the samples under study during their thermal treatment, leading to a considerable decrease in the concentration of the centers, which are due to carbon-hydrogen compounds and, later, to compounds of silicon and oxygen.

An important feature of the OSEE method is relative thinness of the analyzed layer of substances and a strong dependence of the spectrum on the surface treatment quality. An analysis of the OSEE spectra (figure 4) and a comparison with the data in [1] suggest that centers of the E' type were present in all the samples studied. The concentrations of the bulk $\mathrm{E}_{\gamma}^{\prime}$ centers corresponding to an isolated three-coordinated silicon atom and the $\mathrm{E}_{2}{ }_{2}$ centers related to the presence of a hydroxyl group proton are much lower than the concentrations of their surface analogs. The most intensive in the samples 1 is the OSEE signal of surface $E_{S}^{\prime}(2)$ centers. The growth of the concentration of surface centers in the samples 2 correlates well with the increase in the porosity of the material. The subsequent decrease in the concentration of the $E_{2 s}$ ' centers in the samples 3 is in agreement with the removal of the hydroxyl group during annealing and a structural rearrangement of the sample. The growth of the concentration of $E_{S}^{\prime}(1)$ centers in the samples 3 (figure 4) slightly contradicts the EPR data; nevertheless, it can be explained by considerably different sensitivities of the research methods.

\section{Conclusion}

The study demonstrated that the thermal treatment of nanostructured silica changes the number and the type of paramagnetic defects, primarily due to a variation in the composition of the material studied. As the thermal treatment temperature rises, the number of organic paramagnetic impurities decreases considerably and oxygen-deficient bulk and surface E' centers are formed.

The fact that the samples under study contain high concentrations of surface E' centers is a specific feature of the nanoporous $\mathrm{SiO}_{2}$ ceramic.

\section{References}

[1] Zatsepin A F, Biryukov D Yu, Kortov V S 2006 FTT 48229

[2] Walters G K, Estle T L 1961 J. Appl. Phys. 321854

[3] Roitsin A B, Maevskii V M 1989 Uspekhi Fiz. Nauk 159297

[4] Radtsig V A 1995 Khim. Fizika 14125

[5] Agnello S, Boscaino R, Cannas M, Gelardi F M and Leone M 2002 Recent. Res. Devel. NonCrystalline Solids 21

[6] Brekhovskikh S M, Tulnin V A 1988 Radiation Centers in Inorganic Glasses (Moscow, Energoatomizdat)

[7] Stesmans A 1993 Phys. Rev. B 482418 